\title{
A questionnaire-based knowledge, attitude and practice study to determine the awareness of pharmacovigilance among the health care professionals in a tertiary care hospital of West Bengal
}

\author{
Anuran Bhadury, Olivia Mukhopadhyay*, Saswati Sarkar
}

Department of Pharmacology, Burdwan Medical College and Hospital, Burdwan, West Bengal, India

Received: 30 September 2021

Revised: 10 October 2021

Accepted: 15 October 2021

*Correspondence:

Dr. Olivia Mukhopadhyay,

Email: mukherjeeolivia20@gmail.com

Copyright: (C) the author(s), publisher and licensee Medip Academy. This is an open-access article distributed under the terms of the Creative Commons Attribution Non-Commercial License, which permits unrestricted non-commercial use, distribution, and reproduction in any medium, provided the original work is properly cited.

\section{ABSTRACT}

Background: Pharmacovigilance programs have been introduced to keep an eye on adverse drug reactions and safe use of drugs. All Healthcare professionals (HCPs) should report each and every adverse events which they come across. Pharmacovigilance programme of India is running actively since 2010 but India contributes only $2 \%$ of Adverse drug reactions (ADR's) reported worldwide. There is need to monitor awareness of HCP's about pharmacovigilance to achieve the goals. Such studies from peripheries of Eastern India are lacking. The aim of the study was to assess the knowledge, attitude and practice and overall awareness among HCP's about pharmacovigilance and to understand actual barriers of ADR reporting.

Methods: A cross-sectional questionnaire-based study was done in Burdwan Medical College and Hospital. Ninetynine HCP's completed the pre-designed questionnaire. There were 15 questions to assess the awareness and cause(s) of underreporting. Data were analysed using appropriate statistical software.

Results: We analysed data of 67 doctors and 32 nurses. We found, $67.2 \%$ doctors and $59.4 \%$ nurses knew definition of pharmacovigilance. About half HCP's had knowledge about existing pharmacovigilance committee in our hospital. Almost all HCP's felt ADR reporting is necessary. Surprisingly $88.1 \%$ doctors and $46.9 \%$ nurses experienced ADR at least once but $25.4 \%$ and $3.1 \%$ reported them respectively. For knowledge and practice related questions, correct responses were significantly higher for doctors. Most common discouraging factors regarding ADR reporting were, didn't know how to report $(52.5 \%)$ where to report (41.4\%).

Conclusions: Attitude of HCP's towards pharmacovigilance activities was appreciable and combining it with periodic sensitizing programs, and training sessions will increase the knowledge, clear doubts about ADR reporting and improve the awareness about pharmacovigilance.

Keywords: Pharmacovigilance, Adverse drug reaction, Awareness, Knowledge, Practice, Underreporting

\section{INTRODUCTION}

Adverse drug reactions (ADRs) are unwanted and troublesome product of drug therapy. Every year on worldwide basis, ADRs contribute to morbidity and mortality. ${ }^{1}$ A strict surveillance of ADRs are becoming essential day by day. Evolution of PV has occurred to keep an eye on adverse reactions and safe usage of drugs.
According to WHO, Pharmacovigilance (PV) is "The science and activities which are related to the detection, assessment, understanding and the prevention of adverse effects or any other drug related problems". ${ }^{2}$ Healthcare professionals (HCPs) like doctors, nurses, dentists and pharmacists should report each and every adverse effect which they come across by filling up the form given 
by Central Drugs Standard Control Organisation (CDSCO). ${ }^{3}$

Pharamcovigilance Programme of India (PvPI) is running actively since 2010 to collect data about adverse effects of the drugs. Awareness of the HCPs about this programme and to gather ADRs data is one of the most important pillar to run PvPI. Their interest and active participation of HCPs will make drug therapy more safer. ${ }^{4}$ Many studies were conducted in different parts of the world and lack of awareness was found among different classes of healthcare professionals. ${ }^{5}$ Previously such types of studies were done among Indian HCPs. ${ }^{6}$

Lack of knowledge and enthusiasm about PV, reluctance to report were the main obstacles observed among HCPs. ${ }^{7}$ Many studies which were done among Indian HCPs have shown that there is increase in knowledge about PV and their attitude about PV were remarkably good but it's reflection in actual work was very poor. It can be said that practice among HCPs about PV even after years is pathetic. Such types of PV related studies should be done in adequate amount to bring a change in practices and awareness among HCPs.

India has ethnic variability, disease prevalence and miscellaneous medicinal practices which lead to ADRs in large numbers. Therefore, it becomes the responsibility of HCPs to report these adverse events. A study conducted in Mysore recommends that KAP studies should be done to monitor the awareness of PV in different community set up. ${ }^{8}$ Uppsala Monitoring Centre (UMC, WHO), Sweden, is the ultimate database for ADR reporting worldwide. Only $6-10 \%$ of all ADRs are reported. ${ }^{9}$

Out of the total reporting India contributes only $2 \% .{ }^{10} \mathrm{KAP}$ studies about awareness of ADR reporting in periphery of Eastern India is scanty. For safe usage of drugs ADR reporting is necessary. For proper ADR reporting knowledge, attitude and training of doctors and nurses about PV is required. Various studies were found from different parts of India but such study from Eastern India is uncommon. Hence, this study was conducted in peripheral Medical College of West Bengal to assess the knowledge, attitude and practice and overall awareness among doctors and nurses about PV. Actual barriers of ADR reporting were also tried to be found out. We used a pre-validated and predesigned KAP questionnaire used by other studies. ${ }^{8,11}$

\section{Aims and objectives}

The aim and objective of the study were: (a) to determine the status of awareness about PV among healthcare professionals; and (b) to understand actual barriers to report ADRs for healthcare professionals.

\section{METHODS}

The approval for conducting this study was obtained from the human institutional ethics committee of Burdwan Medical College, Burdwan.

\section{Study design}

The study design was cross sectional questionnaire-based study.

\section{Study site}

The study was carried out at Burdwan Medical College and Hospital, Burdwan, West Bengal, a tertiary Medical College and Hospital in Eastern India.

\section{Study population}

The study population included doctors and nurses who gave their consent and were working at the hospital during the study period.

\section{Duration of the study}

The duration of the study was 4 months from March 2018 to July 2018.

\section{Inclusion criteria}

Randomly doctors and nurses who gave their consent were selected and questionnaires were given to them were included.

\section{Exclusion criteria}

HCPs who did not give consent were excluded.

\section{Tools}

A pre-validated and pre-designed questionnaire used by previous studies. There were 15 questions out of which 14 were to assess knowledge, attitude and practices and one question was there to find the root cause of underreporting. Knowledge related questions were 7, attitude related questions were 3 and 4 questions were about practices. Questionnaire has been attached in Appendix.

\section{Study conduct}

Questionnaires were given to 120 interested HCPs. Each and every doubt about the questions were clarified and briefed. They got $30 \mathrm{~min}$ to answer all questions and at that time no one was allowed to consult with each other. They were allowed to submit the paper anonymously but their designations were to be mentioned mandatorily. Ninetynine participants submitted the completed questionnaires. 
After their submission all questionnaires were evaluated manually.

\section{Analysis of data}

All raw data collected were put in an excel sheet and all analysis were done by SPSS version 21 using descriptive statistics and Chi-square test. All tables and figures were made in Microsoft excel 2007. Unanswered questionnaire was excluded from the study to make the calculation easier.

\section{RESULTS}

A total of 120 doctors and nurses agreed to participate in this questionnaire-based study. Out of which 99 of them returned the questionnaire after solving. So, analysis was done on 99 participants. Out of these 99 participants, 67 $(67.7 \%)$ were doctors and $32(32.3 \%)$ were nurses. Most of the participants were young $(56.6 \%)$, between $18-30$ years (Table 1).

According to our study, $67.2 \%$ of doctors and $59.4 \%$ of nurses knew definition of PV. We found $44.8 \%$ doctors and $43.8 \%$ nurses had the knowledge about existence of PV committee in our hospital. PV Programme of India was known to $68.7 \%$ and $53.1 \%$ of doctors and nurses respectively. Out of total $83.6 \%$ of doctors and $87.5 \%$ of nurses knew about who are the healthcare professionals responsible for reporting ADRs (Table 2).

Almost all health care professionals felt reporting of ADRs necessary (99\%). Among doctors, 94\% responded that PV should be taught in details to health care professionals similar to nurses $(93.8 \%)$ (Table 3 ).

About one-third of study participants had seen an ADR reporting form. Among healthcare professionals, $88.1 \%$ of doctors and $46.9 \%$ of nurses experienced ADR at least once in a lifetime but $25.4 \%$ and $3.1 \%$ of doctors and nurses respectively reported them to AMCs (Table 4).

Overall, for knowledge related questions, correct responses were significantly higher than correct responses for nurses $(p=0.012)$. No significant difference was found in correct responses to attitude related questions among doctors and nurses. When we compared practices of PV activities, results were again statistically significant in favour of doctors with $\mathrm{p}$ value $=0.000$ (Table 5).

We tried to figure out the discouraging factors among healthcare professionals regarding ADR reporting. Most common of them were, don't know how to report $(52.5 \%)$, don't know where to report (41.4\%), felt managing patient is more important (19.2\%), lack of access to ADR reporting forms $(12.1 \%)$ and others (Figure 1).

Table 1: Distribution of HCWs (N=99).

\begin{tabular}{|l|l|l|l|}
\hline Groups & Sub-groups & Frequency & Percentage (\%) \\
\hline \multirow{3}{*}{ Age (years) } & $18-30$ & 56 & 56.6 \\
& $31-40$ & 25 & 25.3 \\
\hline \multirow{2}{*}{ Gender } & $41-50$ & 14 & 14.1 \\
\hline \multirow{2}{*}{ Profession } & $51-60$ & 4 & 4.0 \\
\hline
\end{tabular}

Table 2: Correct response of HCWs for knowledge related questions in percentage.

\begin{tabular}{|c|c|c|c|}
\hline Questions & Doctors $(\%)$ & Nurses (\%) & Total (\%) \\
\hline Define or know about PV & 67.2 & 59.4 & 64.7 \\
\hline Purpose of PV & 56.7 & 31.3 & 48.5 \\
\hline Healthcare professionals responsible for reporting ADR's & 83.6 & 87.5 & 84.8 \\
\hline Know about PV Programme of India (PvPI)? & 68.7 & 53.1 & 63.6 \\
\hline Regulatory body responsible for PV in India? & 79.1 & 56.3 & 71.7 \\
\hline Is there any PV committee in your hospital? & 44.8 & 43.8 & 44.4 \\
\hline International centre for ADR monitoring? & 17.9 & 15.6 & 17.2 \\
\hline
\end{tabular}

Table 3: Positive response of HCWs to attitude related questions in percentage.

\begin{tabular}{|c|c|c|c|}
\hline Questions & Doctors (\%) & Nurses (\%) & Total (\%) \\
\hline Is reporting of ADR's necessary? & 98.5 & 100 & 99 \\
\hline PV should be taught in details to healthcare professionals? & 94 & 93.8 & 93.9 \\
\hline $\begin{array}{l}\text { Opinion about establishing ADR monitoring centre in every } \\
\text { hospital? }\end{array}$ & 73.1 & 84.4 & 76.8 \\
\hline
\end{tabular}


Table 4: Positive response of HCWs to practice related questions in percentage.

\begin{tabular}{|c|c|c|c|}
\hline Questions & Doctors (\%) & Nurses $(\%)$ & Total (\%) \\
\hline Have you ever experienced ADR's? & 88.1 & 46.9 & 74.7 \\
\hline Have you ever reported an ADR? & 25.4 & 3.1 & 18.2 \\
\hline Seen the ADR reporting form? & 43.3 & 12.5 & 33.3 \\
\hline Trained on how to report ADR's? & 28.4 & 28.1 & 28.3 \\
\hline
\end{tabular}

Table 5: Comparison of responses of HCPs to KAP questionnaire by Chi-square test.

\begin{tabular}{|c|c|c|c|c|c|c|}
\hline \multirow{2}{*}{ Categories } & \multirow{2}{*}{ Responses } & \multicolumn{2}{|c|}{ Doctors } & \multicolumn{2}{|c|}{ Nurses } & \multirow{2}{*}{$P$ value } \\
\hline & & $\mathbf{N}$ & $\%$ & $\mathbf{N}$ & $\%$ & \\
\hline \multirow{2}{*}{ Knowledge } & Correct & 280 & 59.7 & 111 & 49.6 & \multirow{2}{*}{$0.012 *$} \\
\hline & Incorrect & 189 & 40.3 & 113 & 50.4 & \\
\hline \multirow{2}{*}{ Attitude } & Yes & 178 & 88.6 & 89 & 92.7 & \multirow{2}{*}{0.309} \\
\hline & No & 23 & 11.4 & 7 & 7.3 & \\
\hline \multirow{2}{*}{ Practice } & Yes & 124 & 46.3 & 29 & 18.5 & \multirow{2}{*}{$0.000 *$} \\
\hline & No & 144 & 53.7 & 99 & 81.5 & \\
\hline
\end{tabular}

Note: $*$ p value $<0.05$ was taken as significant.

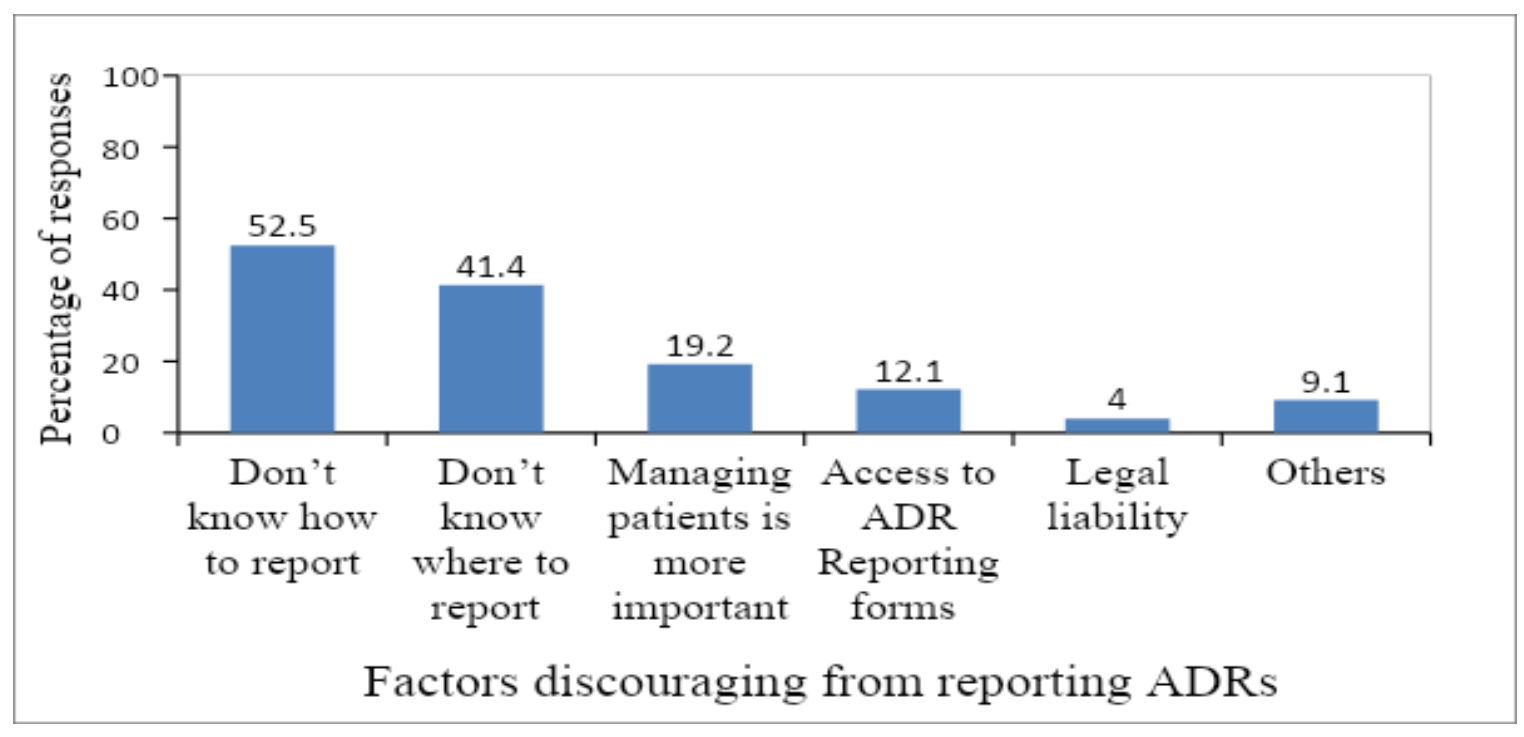

Figure 1: Factors discouraging HCP's from reporting ADR's (percentage).

\section{DISCUSSION}

Our study determined the status of awareness about PV among doctors and nurses in our hospital with the help of a questionnaire regarding knowledge, attitude and practices of PV and we compared our results with other studies published throughout India (Table 6). Some questions that we asked to the participants were different from other studies. Our results reveal majority of the study participants feel ADR reporting is necessary. But we found a huge gap between experiencing ADR at least once $(74.7 \%)$ and ever reported $(18.2 \%)$ which is consistent with other studies too. Almost all studies had similar results in case of attitude related questions. We found only $28.3 \%$ of health care professionals were trained for reporting ADR which is very discouraging with respect to Gupta et al (53.5\%) and Srinivasan et al (64.3\%) although some studies reported even lesser percentage of training than ours. ${ }^{6,7,12-14}$ Studies where number of HCPs were trained about $\mathrm{PV}$, the ADR reporting practices also improved. ${ }^{7,13}$ Participant's views were different when they were asked about establishment of ADR monitoring centre in each hospitals (Table 6).

Our study had the highest number of people who agreed that each hospital should have an ADR monitoring centre $(76.8 \%)$ and Vakade et al have the lowest number of people who agreed for the same (46.6\%). Most of the participants in all studies had agreed that proper way of reporting ADR should be taught to them. According to our comparison Kanwar et al. had the maximum and Vakade et al had the minimum number of participants respectively who knew about the definition and purpose of PV and our data lies somewhere in between their values. We found similar percentage of participants $(84.8 \%)$ who knew about who are the HCPs responsible for reporting ADRs like Gupta et al and Kanwar et al. Whereas, Srinivasan et al had the lowest percentage for the same..$^{6,12,13}$ Gupta et 
al had $75.2 \%$ of people who knew about PvPI, then our study $(63.6 \%)$ and Vakade et al had fewer people who knew that $(34.1 \%)^{7,14}$

Though overall percentage of HCPs trained for PV, was found to be low, in spite of being equally trained, only $3.1 \%$ of nurses ever reported an ADR compared to $25.4 \%$ in case of doctors. By analysing the number of correct responses to knowledge related questions, we found knowledge of nurses about PV was significantly lower than that of doctors. Though regarding attitude, we didn't find any significant difference between them $(p=0.309)$, practices related to $\mathrm{PV}$ was again found to be significantly poorer for nurses than doctors $(\mathrm{p}=0.000)$.

In our study, we found very strong reasons for reluctance of HCPs in ADR reporting and compared with others (Table 7). Main cause of apathy was because of unawareness of HCPs about how and where to report the ADRs. In our study $52.5 \%$ of participants did not know how to report, which is similar to Bharadwaj et al (53\%), better than Desai et al (68\%), worser than Sachidananda et al $(22.3 \%)$ and Kunnoor et al $(33 \%)$. Percentage of HCPs who did not know where to report was more in case of Desai et al $(70 \%)$ and less in case of Bharadwaj et al (30\%), Sachidananda et al $(19.8 \%)$, than our study $(41.4 \%)$ and Kunnoor et al (42\%). ${ }^{6,11,15,16}$ Very few people thought ADR reporting is unimportant both in our study and Bharadwaj et al whereas a bunch of people (13\%) thought reporting is useless in the study of Desai et al. ${ }^{6,11,15,16} \mathrm{~A}$ good number of people $(19.2 \%)$ felt management of patient is more challenging and important rather than ADR reporting as there is often shortage of time which is similar to other studies. A huge difference has been obtained in our study $(12.1 \%)$ when compared to Desai et al (49.2\%) but
Sachidananda et al had similar results $(13.2 \%)$ in case of accessibility to ADR forms. ${ }^{11,15}$

We also found preoccupied thoughts of legal (4\%) and professional liability (2\%) also among doctors and nurses which stopped them to report ADRs though in fewer percentages than for Desai et al, $17.3 \%$ and $14.2 \%$ repectively but similar to Sachidananda et al. ${ }^{11,15}$ Some other areas of concern for underreporting ADRs were found in some studies e.g., no incentive for reporting ADRs. We did not include or obtain such feeling of HCPs in our study. Awareness about PV and ADR reporting can be improved by educating and orienting the medical and para-medical staff through conduction of CME's on this topic.

Future holds an immense task to invent interesting approaches and to train the health care workers by furnishing them more information, guidance related to ADR detection, its prevention and reporting. Other ways through which awareness can be increased are lectures, conferences, workshops, post training reminders, easy availability of reporting forms. We should stress upon digital submission and fast feedback about ADR reporting. Also, to increase interest we should think about incentives should be given or not. We should think some beneficial ways which can make the process of ADR reporting smoother and less cumbersome. We should feed the thought among doctors, nurses, pharmacists and dentists that overall health care expenditure can be reduced by PV activities through early detection, assessment and reporting which helps in prevention and timely management of ADRs, improve patient morbidity and mortality in the long race. Health care professionals should work together by joining hands to make PvPI successful.

Table 6: Comparison of responses of HCPs to KAP questionnaire with similar studies.

\begin{tabular}{|c|c|c|c|c|c|c|}
\hline All questions & $\begin{array}{l}\text { Our } \\
\text { study }\end{array}$ & $\begin{array}{l}\text { Gupta } \\
\text { et al }\end{array}$ & $\begin{array}{l}\text { Srinivasan } \\
\text { et } \text { al }^{13}\end{array}$ & $\begin{array}{l}\text { Vakade } \\
\text { et al }{ }^{14}\end{array}$ & $\begin{array}{l}\text { Kanwar } \\
\text { et al }\end{array}$ & $\begin{array}{l}\text { Bharadwaj } \\
{\text { et } \text { al }^{6}}\end{array}$ \\
\hline Define or know about PV & 64.7 & 62.4 & 53.4 & 34.1 & 81.3 & 80 \\
\hline Purpose of PV & 48.5 & 61.3 & 51.7 & 41.3 & 66 & 43 \\
\hline HCP's responsible for reporting ADRs & 84.8 & 80.2 & 33.9 & NA & 88 & NA \\
\hline Know about PvPI? & 63.6 & 75.2 & NA & 34.1 & 50 & 41 \\
\hline Regulatory body for PV in India? & 71.7 & 78.2 & 59.5 & 51.1 & 67.5 & NA \\
\hline $\begin{array}{l}\text { Is there any PV committee in your } \\
\text { hospital? }\end{array}$ & 44.4 & NA & NA & 21.6 & NA & NA \\
\hline $\begin{array}{l}\text { International centre for ADR } \\
\text { monitoring? }\end{array}$ & 17.2 & 41.6 & 32.1 & 26.1 & 37.5 & NA \\
\hline Is reporting of ADR's necessary? & 99 & 97 & 83.9 & 88.6 & NA & 90 \\
\hline $\begin{array}{l}\text { PV should be taught } \\
\text { in details to HCP's? }\end{array}$ & 93.9 & 92.1 & 91.3 & 85.2 & 92.5 & 75 \\
\hline Establishing AMC in every hospital? & 76.8 & 74.3 & 72.1 & 46.6 & 55 & 55 \\
\hline Have you ever experienced ADR's? & 74.7 & 64.4 & 59.5 & 50 & 70 & 80 \\
\hline Have you ever reported an ADR? & 18.2 & 22.8 & 36.5 & 2.3 & 1.3 & 15 \\
\hline Seen the ADR reporting form? & 33.3 & 58.4 & 75.2 & 34.1 & NA & 26 \\
\hline Trained on how to report ADR's? & 28.3 & 53.5 & 64.3 & 17 & 18.8 & NA \\
\hline
\end{tabular}


Table 7: Comparison of discouraging factors for ADR reporting with similar studies.

\begin{tabular}{|c|c|c|c|c|c|}
\hline Factors & $\begin{array}{l}\text { Our } \\
\text { study }\end{array}$ & $\begin{array}{l}\text { Desai } \\
\text { et } \mathbf{a l}^{11}\end{array}$ & $\begin{array}{l}\text { Bharadwaj } \\
\text { et al }\end{array}$ & $\begin{array}{l}\text { Sachidananda } \\
\text { et al } \mathbf{l}^{15}\end{array}$ & $\begin{array}{l}\text { Kunnoor } \\
\text { et } \mathbf{a l}^{16}\end{array}$ \\
\hline Don't know how to report & 52.5 & 68 & 53 & 22.3 & 33 \\
\hline Don't know where to report & 41.4 & 70 & 30 & 19.8 & 42 \\
\hline Don't think it to be important & 2 & 13 & 1.3 & 5 & NA \\
\hline $\begin{array}{l}\text { Managing patient is more important than reporting } \\
\text { ADR }\end{array}$ & 19.2 & 28.8 & 17 & 28.1 & 34 \\
\hline Lack of access to ADR reporting forms & 12.1 & 49.2 & NA & 13.2 & NA \\
\hline Legal liability issues & 4 & 17.3 & NA & 4.1 & 27 \\
\hline Concerns about professional liability & 2 & 14.2 & 7.5 & 4.1 & NA \\
\hline
\end{tabular}

\section{Strength and limitations}

Our study included many questions regarding knowledge. Barriers of reporting were tried to be found out with proposed solutions to combat underreporting. We had compared our study with other studies through different parts of India. Study population was less and was the main weakness of the study. New questions could have been included in the questionnaire and other factors related with self-reporting studies like difficulty to recall could have affected the results in some ways.

\section{CONCLUSION}

This study concludes that awareness of PV among HCPs can be increased by periodic sensitizing programs, workshops and training sessions to increase the knowledge and clearing doubts of HCPs. The positive attitude towards PV activities was appreciable among HCPs and proper training along with easy access to ADR reporting forms can improve ADR reporting practices to a great extent.

\section{ACKNOWLEDGEMENTS}

Authors would like to extend deep gratitude to HCWs for helping by giving information and participate in this study willingly.

Funding: No funding sources

Conflict of interest: None declared

Ethical approval: The study was approved by the Institutional Ethics Committee

\section{REFERENCES}

1. Lazarou J, Pomeranz BH, Corey PN. Incidence of adverse drug reactions in hospitalized patients: a metaanalysis of prospective studies. JAMA. 1998;279(15):1200-5.

2. WHO. Quality Assurance and Safety of Medicines Team. Safety of medicines: a guide to detecting and reporting adverse drug reactions: why health professionals need to take action, 2002. Available at: https://apps.who.int/iris/handle/1066578. Accessed on 20 September 2021.
3. Upadhyaya P, Seth V, Moghe VV, Sharma M, Ahmed M. Knowledge of adverse drug reaction reporting in first year postgraduate doctors in a medical college. Ther Clin Risk Manag. 2012;8:307-12.

4. Remesh A. Identifying the reasons for under reporting of ADR: A cross sectional survey. Res J Pharm Biol Chem Sci. 2012;3:1379-86.

5. Xu H, Wang Y, Liu N. A hospital-based survey of healthcare professionals in the awareness of pharmacovigilance. Pharmacoepidemiol Drug Saf. 2009;18(7):624-30.

6. Bharadwaj V, Budania N, Mondal A, Yadav V, Sharma P. A Survey to Assess the Awareness of Adverse Drug Reactions and Pharmacovigilance Practices among Healthcare Professionals in a Tertiary Care Hospital. Int J Med Res Prof. 2016;2(1):134-7.

7. Gupta SK, Nayak RP, Shivaranjani R, Vidyarthi SK. A questionnaire study on the knowledge, attitude, and the practice of pharmacovigilance among the healthcare professionals in a teaching hospital in South India. Perspect Clin Res. 2015;6(1):45-52.

8. Ramesh M, Parthasarathi G. Adverse drug reaction reporting: the attitudes and the perceptions of the medical practitioners. Asian J Pharma Clin Res. 2009;2(2):10-4.

9. Feely J, Moriarty S, Connor P. Stimulating reporting of adverse drug reactions by using a fee. BMJ. 1990;300(6716):22-3.

10. Smith CC, Bennett PM, Pearce HM, Harrison PI, Reynolds DJ, Aronson JK, et al. Adverse drug reactions in a hospital general medical unit meriting notification to the Committee on Safety of Medicines. Br J Clin Pharmacol. 1996;42(4):423-9.

11. Desai CK, Iyer G, Panchal J, Shah S, Dikshit RK. An evaluation of knowledge, attitude, and practice of adverse drug reaction reporting among prescribers at a tertiary care hospital. Perspect Clin Res. 2011;2(4):129-36.

12. Kanwar S, Mathur SK, Yadav D. A questionnaire based study on the knowledge, attitude and practice of $\mathrm{PV}$ among the medical officers working in peripheral areas of Ajmer district, Rajasthan (India). Gal Int $\mathbf{J}$ Health Sci Res. 2020;5(1):84-8.

13. Srinivasan V, Sheela D, Mridula D. Knowledge, Attitude and Practice of PV among the Healthcare Professionals in a Tertiary Care Hospital - A 
Questionnaire Study. Biomed Pharmacol J. 2017;10(3):1441-7.

14. Vakade KP, Sangisetti VM, Binayke MV, Abhavathi VN, Nayak BB. An evaluation of knowledge, attitude and practice of PV among interns in a tertiary care teaching hospital of North Maharashtra. Int $\mathbf{J}$ Basic Clin Pharmacol. 2016;5:2321-5.

15. Sachidananda AMN, Sachidananda AU. Awareness of Adverse Drug Reaction Monitoring and Practice among Student Nurses. Indian J Pharm Pharmacol. 2016;3(3):121-6.
16. Kunnoor NS, Sharanabasappa, Lohit K. Perception of doctors towards Adverse Drug Reaction (ADR) reporting: a cross sectional survey using a validated questionnaire. Int $\mathrm{J}$ Basic Clin Pharmacol. 2017;6:2671-5.

Cite this article as: Bhadury A, Mukhopadhyay O, Sarkar S. A questionnaire-based knowledge, attitude and practice study to determine the awareness of pharmacovigilance among the health care professionals in a tertiary care hospital of West Bengal Int J Basic Clin Pharmacol 2021;10:1250-8. 


\section{APPENDIX}

KAP questionnaire to determine the awareness of PV among the health care professionals.

\begin{tabular}{|c|c|}
\hline S. no. & KAP questionnaire \\
\hline 1. & Define or know about PV \\
\hline a. & The science detecting the type and incidence of ADR after drug is marked \\
\hline b. & The science of monitoring ADR's occurring in a hospital \\
\hline c. & The process of improving the safety of the drug \\
\hline d. & The detection, assessment, understanding and prevention of adverse effects \\
\hline 2. & The most important purpose of $\mathrm{PV}$ is \\
\hline a. & To identify safety of the drug. \\
\hline b. & To calculate incidence of ADR's \\
\hline c. & To identify predisposing factor's to ADR's \\
\hline d. & To identify previously unrecognized ADR's \\
\hline 3. & The healthcare professionals responsible for reporting ADR's in a hospital is/are \\
\hline a. & Doctor \\
\hline b. & Nurses \\
\hline c. & Pharmacist \\
\hline d. & All of the above \\
\hline 4. & Do you know regarding the existence of a National PV Programme in India? \\
\hline a. & Yes \\
\hline b. & No \\
\hline c. & Can't say \\
\hline d. & May be \\
\hline 5. & In India which regulatory body is responsible for monitoring ADRs? \\
\hline a. & Central Drugs Standard Control Organization (CDSCO) \\
\hline b. & Indian Council of Medical Research (ICMR) \\
\hline c. & Indian Clinical Research Institute (ICRI) \\
\hline d. & Medical Council of India (MCI) \\
\hline 6. & Is there any PV Committee in your Hospital? \\
\hline a. & Yes \\
\hline b. & No \\
\hline c. & Not yet formed \\
\hline d. & Don't know \\
\hline 7. & Where is the international collaborating centre for ADR monitoring located? \\
\hline a. & Moscow, Russia \\
\hline b. & New Delhi, India \\
\hline c. & Uppsala, Sweden \\
\hline d. & Geneva, Switzerland \\
\hline 8. & Do you think reporting of adverse reaction is necessary \\
\hline a. & Yes \\
\hline b. & No \\
\hline c. & Can't say \\
\hline d. & May be \\
\hline 9. & Do you think PV should be taught in detail to healthcare professionals? \\
\hline a. & Yes \\
\hline b. & No \\
\hline c. & Can’t say \\
\hline d. & May be \\
\hline 10. & What is your opinion about establishing ADR monitoring centre in every hospital? \\
\hline a. & Yes \\
\hline b. & No \\
\hline c. & Can't say \\
\hline d. & May be \\
\hline 11. & Have you ever experienced adverse drug reactions in your patient during your professional practice? \\
\hline a. & Yes \\
\hline b. & No \\
\hline
\end{tabular}




\begin{tabular}{|c|c|}
\hline S. no. & KAP questionnaire \\
\hline c. & Can’t say \\
\hline d. & May be \\
\hline 12. & Have you ever reported ADR to the PV centre? \\
\hline a. & Yes \\
\hline b. & No \\
\hline c. & Don't know where to submit the ADR reporting form \\
\hline d. & Don't know how to fill up the ADR reporting form \\
\hline 13. & Have you ever seen the ADR reporting form? \\
\hline a. & Yes \\
\hline b. & No \\
\hline c. & Can’t say \\
\hline d. & May be \\
\hline 14. & Have you ever been trained on how to report Adverse Drug Reaction (ADR)? \\
\hline a. & Yes \\
\hline b. & No \\
\hline c. & Can’t say \\
\hline d. & May be \\
\hline 15. & Which of the following factor discourage you from reporting ADRs? (You may tick multiple reasons) \\
\hline a. & Did not know how to report \\
\hline b. & Not knowing where to report \\
\hline c. & Did not think it to be important \\
\hline d. & Managing patient was more important than reporting ARD \\
\hline e. & Lack of access to ADR Reporting forms \\
\hline f. & Patient confidentiality issues \\
\hline g. & Legal liability issues \\
\hline h. & Concerns about professional liability \\
\hline i. & Others \\
\hline j. & Not applicable \\
\hline
\end{tabular}

